\title{
Pegfilgrastim Biosimilar LA-EP2006
}

National Cancer Institute

\section{Source}

National Cancer Institute. Pegfilgrastim Biosimilar LA-EP2006. NCI Thesaurus. Code C104005.

\begin{abstract}
A biosimilar of pegfilgrastim, a long-acting pegylated form of recombinant human granulocyte colony-stimulating factor (G-CSF) filgrastim, with hematopoietic activity. In a similar manner to G-CSF, pegfilgrastim biosimilar LA-EP2006 binds to and activates specific cell surface receptors, stimulating neutrophil progenitor proliferation and differentiation and selected neutrophil functions. Therefore, this agent may prevent the incidence and shorten the duration of chemotherapy-induced neutropenia. Conjug ation of the cytokine with a branched polyethylene glycol molecule significantly increases this agent's therapeutic half-life compared to filgrastim.
\end{abstract}

